\title{
Anti-VEGFC Monoclonal Antibody VGX-100
}

National Cancer Institute

\section{Source}

National Cancer Institute. Anti-VEGFC Monoclonal Antibody VGX-100. NCI Thesaurus.

Code C99765.

A fully human monoclonal antibody directed against the human vascular endothelial growth factor C (VEGFC or Flt4 lig and) with potential antiang iog enic activity. Anti-VEGFC monoclonal antibody VGX-100 specifically binds to and inhibits VEGFC protein, thereby preventing its binding to VEGFR3 (FLT4) or VEGFR2 (KDR or FLK1). This may prevent VEGFC-mediated signaling and may lead to the inhibition of vascular and lymphatic endothelial cell proliferation. The inhibition of tumor angiogenesis and lymphang iogenesis may eventually decrease tumor cell proliferation and prevent metastasis. VEGFC is overexpressed in a variety of cancer cells, and is associated with increased invasiveness and decreased survival. 